\title{
Crescimento de planta, partição de assimilados e produção de frutos de melão amarelo sombreado por diferentes malhas
}

\author{
Growth of plant, partition of assimilates and fruit yield of \\ melon yellow shaded by different meshes \\ Francisco Hevilásio Freire Pereira ${ }^{\mathrm{I}}$ Francisco Vanies da Silva Sá ${ }^{*}$

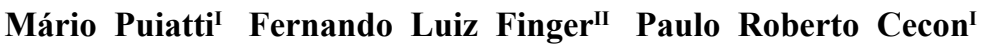

\section{RESUMO}

Objetivou-se avaliar variações no crescimento, na partição de assimilados e na produção de frutos de melão, tipo Amarelo 'Gold Mine', sob cultivos sombreados por diferentes malhas. O experimento foi conduzido na Horta de Pesquisas do Departamento de Fitotecnia da Universidade Federal de Viçosa, no periodo de 24/11/2008 a 11/03/2009. Os tratamentos foram constituidos de quatro ambientes de cultivo: controle (pleno sol) e sob as malhas Aluminet $t^{\circledR} 30 \%-O$, Cromatinet ${ }^{\circledR} 30 \%-O$ e Sombrite $^{\circledR} 30 \%$, com reduções, na radiação solar incidente, de $30,8,35$, e 32,0\%, respectivamente. O delineamento experimental foi o inteiramente casualizado, com quatro repetições. Para as características avaliadas periodicamente, utilizou-se o esquema de parcela subdividida com os ambientes alocados nas parcelas e as avaliações periódicas nas subparcelas. Dentre os ambientes sombreados, o cultivo do meloeiro sob a malha Aluminet ${ }^{\circledR} 30 \%-O$ foi o tratamento que mais se destacou em termos de crescimento de planta e produção de frutos.

Palavras-chave: Cucumis melo, sombreamento, área foliar, massa seca, produtividade.

\section{ABSTRACT}

In order to study variations in growth, partitioning of assimilates and fruit production of melons, Yellow types 'Gold Mine' under crops shaded by different meshes were evaluated. The experiment was carried out in field Research, Department of Plant Science, Universidade Federal de Viçosa, in the period from 24/11/2008 to 11/03/2009. The treatments were four culture environments: control (full sun) and under the Aluminet ${ }^{\circledR} 30 \%-O$, Cromatinet $^{\circledR} 30 \%$ and Sombrite ${ }^{\circledR}$, 30\% meshes with reductions in solar radiation, $30.85,35.9$ and $32.0 \%$, respectively. The experimental design was completely randomized, with four replications. For the characteristics evaluated periodically it was used the split-plot design with environments allocated to plots and subplots periodic reviews. Among the shaded environments, melon cultivation in the mesh Aluminet $^{\circledR} 30 \%$-O was the treatment that stood out in terms of plant growth and fruit yield.

Key words: Cucumis melo, shading, leaf area, dry mass, productivity.

\section{INTRODUÇÃO}

Os processos fisiológicos responsáveis pelo crescimento e produtividade das plantas cultivadas são diretamente influenciados pelos fatores climáticos (SILVA JUNIOR et al., 2012). A radiação solar é a fonte primária de energia responsável pela manutenção do processo fotossintético. Pela fotossíntese, as plantas convertem a energia física da luz solar em energia química, e esse processo é essencial para a manutenção de todas as formas de vida existentes no planeta (TAIZ \& ZEIGER, 2009). Contudo, existem evidências de que alta radiação pode afetar o crescimento das plantas e, no caso das culturas, também a produtividade (PEREIRA et al., 2011). A luz solar em excesso pode ser prejudicial à fotossíntese, pois a eficiência do processo fotossintético pode ser severamente reduzida quando as plantas são expostas a altos níveis de radiação, particularmente sob condições adversas do meio ambiente (BRANT et al., 2011).

Quando as folhas são expostas à quantidade de luz maior do que podem utilizar, ou seja, acima do ponto de saturação, o aparato fotossintético é danificado,

\footnotetext{
IUnidade Acadêmica de Ciências Agrárias, Universidade Federal de Campina Grande (UFCG), Rua Jario Vieira Feitosa, 1770, Bairro dos Pereiros, 58840-000, Pombal, PB, Brasil. E-mail: vanies_agronomia@hotmail.com. *Autor para correspondência.
}

IIUniversidade Federal de Viçosa (UFV), Viçosa, MG, Brasil. 
tornando-se inativo. Esse fenômeno de redução da fotossíntese pelo excesso de irradiância é denominado de fotoinibição (TAIZ \& ZEIGER, 2009). As primeiras pesquisas sobre fotoinibição interpretavam todos os decréscimos em fotossíntese como dano ao aparato fotossintético. Agora, reconhece-se que o decréscimo na eficiência fotossintética pode também ser reflexo da utilização pela planta de mecanismos protetores, como a síntese de pigmentos carotenoides e enzimas antioxidativas que, em contrapartida, são responsáveis pelo consumo de grande quantidade de energia química na forma de ATP, tornando-se, assim, essa proteção, uma atividade de alto custo para as plantas (TAIZ \& ZEIGER, 2009).

O meloeiro é considerado uma planta exigente em radiação solar e temperatura. Esses fatores ambientais são os que mais influenciam os parâmetros fisiológicos, tais como fotossíntese, respiração, fotorespiração, transpiração e condutância estomática, sendo considerados como fatores determinantes do crescimento das plantas e na obtenção de elevadas produtividades (SILVA et al., 2003). Em melão 'Cantaloupe' e 'Honey Dew', constatou-se que o ponto de saturação luminoso é atingido entre 1.000 e $1.200 \mu \mathrm{mol} \mathrm{m} \mathrm{m}^{-2}$ $\mathrm{s}^{-1}$ (VOLATIN et al., 1998), portanto, bem abaixo das condições tropicais, que chega a atingir valores superiores a $1.800 \mu \mathrm{mol} \mathrm{m} \mathrm{m}^{-2} \mathrm{~s}^{-1}$ (PEREIRA et al., 2011). No entanto, trabalhos avaliando os efeitos do sombreamento no meloeiro, objetivando a obtenção de níveis ótimos de crescimento da planta e produtividade de frutos, otimizando assim as relações fonte-dreno, são escassos.

O trabalho teve como objetivo avaliar variações no crescimento, na partição de assimilados e na produção de frutos de melão, tipo Amarelo 'Gold Mine' sob cultivos sombreados por diferentes malhas.

\section{MATERIAL E MÉTODOS}

O experimento foi conduzido na Horta de Pesquisas do Departamento de Fitotecnia da Universidade Federal de Viçosa, no período de 24/11/2009 a 11/03/2009. Utilizou-se o híbrido de melão 'Gold Mine', pertencente ao Grupo Inodorus. O cultivo foi em solo classificado como Argissolo Vermelho-Amarelo, Câmbico, fase terraço, textura argilosa (areia grossa $=29$; areia fina $=15$; silte $=$ 17 e argila $=39 \mathrm{dag} \mathrm{kg}^{-1}$ ), cujos resultados médios das análises químicas, antes da instalação do experimento, foram: $\mathrm{pH}$ em $\mathrm{H}_{2} \mathrm{O}(1: 2,5)=5,8 ; \mathrm{P}$ $=58,5 \mathrm{e} \mathrm{K}=76,0 \mathrm{mg} \mathrm{dm}^{-3} ; \mathrm{Ca}=4,0 ; \mathrm{Mg}=0,8 ; \mathrm{Al}$ $=0,0 ; \mathrm{H}+\mathrm{Al}=6,63 ; \mathrm{SB}=4,99 ; \mathrm{CTC}_{\text {efetiva }}=4,99$; $\mathrm{CTC}_{\text {total }}=8,62 \mathrm{cmol}_{\mathrm{c}} \mathrm{dm}^{-3}$ e $\mathrm{MO}=3,33 \mathrm{dag} \mathrm{kg}^{-1}$. As características climáticas registradas durante a condução do experimento encontram-se na tabela 1 .

O preparo do solo constou de aração, gradagem e abertura de sulcos de plantio espaçados de $1,0 \mathrm{~m}$, sobre canteiros construídos à altura de $0,20 \mathrm{~m}$ e largura de $0,40 \mathrm{~m}$. A adubação de plantio foi baseada na análise de solo e recomendações para a cultura do meloeiro (RIBEIRO et al., 1999), em sulcos de plantio, e constou de 240 de $\mathrm{P}_{2} \mathrm{O}_{5} ; 19,0$ de $\mathrm{K}_{2} \mathrm{O}$ (10\% do total), 15,0 de $\mathrm{N}$ ( $10 \%$ do total), 200 de sulfato de magnésio; 20 de bórax; 15 de sulfato de zinco; e 3,0 $\mathrm{kg} \mathrm{ha}^{-1}$ de molibidato de amônio. Durante o ciclo da cultura, juntamente com a água de irrigação (fertirrigação), foram feitas as adubações complementares com $\mathrm{N}$ e K, iniciando-se aos sete dias após o transplantio. Foram aplicados $135,0 \mathrm{~kg}$ de $\mathrm{N}+171,0 \mathrm{~kg}$ de $\mathrm{K}_{2} \mathrm{O} \mathrm{ha}^{-1}$, divididos

Tabela 1 - Dados climáticos coletados durante a condução do experimento sob condições de pleno sol (controle) e nos ambientes sob as malhas Aluminet ${ }^{\mathbb{Q}} 30 \%-\mathrm{O}$, Cromatinet ${ }^{\mathbb{Q}} 30 \%$-O e Sombrite ${ }^{\mathbb{R}} 30 \%$.

\begin{tabular}{|c|c|c|c|c|c|}
\hline \multicolumn{2}{|c|}{------------------Variáveis climáticas------------------- } & \multirow{2}{*}{$\begin{array}{l}\text { Controle } \\
17,58\end{array}$} & \multirow{2}{*}{$\begin{array}{l}\text { Aluminet } \\
18,17\end{array}$} & \multirow{2}{*}{$\begin{array}{c}\text { Cromatinet } \\
17,74\end{array}$} & \multirow{2}{*}{$\begin{array}{l}\text { Sombrite } \\
18,28\end{array}$} \\
\hline Temperatura de $\operatorname{ar}\left({ }^{\circ} \mathrm{C}\right)$ & Mínima & & & & \\
\hline тепрегаtura do al (C) & Máxima & 33,40 & 32,41 & 31,67 & 33,14 \\
\hline \multirow{2}{*}{ Temperatura do solo $\left({ }^{\circ} \mathrm{C}\right)$} & Mínima & 23,47 & 22,31 & 22,55 & 22,68 \\
\hline & Máxima & 24,20 & 23,11 & 23,35 & 23,38 \\
\hline \multirow{2}{*}{ Umidade relativa do ar $(\%)$} & Mínima & 45,30 & 49,24 & 49,72 & 49,76 \\
\hline & Máxima & 80,43 & 87,25 & 86,79 & 88,24 \\
\hline $\operatorname{PAR}\left(\mu \mathrm{mol} \mathrm{m} \mathrm{m}^{-2} \mathrm{~s}^{-1}\right)^{1}$ & & 775,93 & 536,95 & 497,37 & 527,37 \\
\hline Insolação média diária (h) & & 4,47 & 4,47 & 4,47 & 4,47 \\
\hline Precipitação pluvial (mm) & & $1.027,60$ & $1.027,60$ & $1.027,60$ & $1.027,60$ \\
\hline
\end{tabular}

${ }^{1} \mathrm{PAR}$ - radição fotossinteticamente ativa. 
em dez aplicações semanais, obedecendo aos seguintes critérios: $5,0 \%$ da quantidade de cada elemento nas duas primeiras semanas e $10 \%$ a cada semana até aos 70 dias do transplante.

A semeadura foi realizada em 24/11/2005, em bandejas de polipropileno expandido de 128 células, preenchidas com substrato comercial, colocando-se uma semente por célula e mantida em ambiente protegido. $\mathrm{O}$ transplantio foi efetuado no espaçamento de $1,0 \times 0,30 \mathrm{~m}$, quando as plântulas apresentavam três folhas definitivas, sendo a primeira completamente expandida. As plantas foram conduzidas na vertical, com auxílio de fitilho, com somente uma haste por planta, desde o início do desenvolvimento, e frutificação nas ramas secundárias. As capinas manuais, as irrigações por gotejamento e o controle fitossanitário foram realizados de acordo com as necessidades e recomendações técnicas para a cultura (SILVA et al., 2003).

A unidade experimental foi constituída de quatro fileiras de $4,5 \mathrm{~m}$ de comprimento, totalizando $18 \mathrm{~m}^{2}$ de área. Consideraram-se como útil as duas fileiras centrais, excluindo-se as plantas das extremidades. Os tratamentos foram constituídos por quatro ambientes de cultivo: controle (pleno sol) e sob as malhas Aluminet ${ }^{\circledR} 30 \%-\mathrm{O}$, Cromatinet $^{\circledR}$ $30 \%$-O e Sombrite ${ }^{\circledR} 30 \%$, com reduções, na radiação solar incidente, em $30,85 \%, 35,9 \%$ e $32,0 \%$, respectivamente. As malhas foram instaladas em "telados" retangulares, com dimensões de $2 \times 4 \times 36 \mathrm{~m}$ (altura $\mathrm{x}$ largura $\mathrm{x}$ comprimento). $\mathrm{O}$ delineamento experimental utilizado foi o inteiramente casualizado, com quatro repetições. Para características avaliadas periodicamente, a cada 14 dias, utilizou-se o esquema de parcelas subdivididas, em que os ambientes foram considerados como parcelas e as avaliações periódicas a cada 14 dias, como subparcelas.

Para avaliação do crescimento de planta e particionamento de biomassa nos órgãos vegetativos e reprodutivos da parte aérea, foram coletados, a cada 14 dias, iniciando no transplante e indo até os 84 dias após transplantio (DAT), uma planta útil por unidade experimental, totalizando quatro plantas por tratamento em cada ambiente de cultivo. As características avaliadas foram: comprimento da haste principal $(\mathrm{cm})$; número de entrenós por planta; comprimento de entrenós $(\mathrm{cm})$; número de folhas por planta; área foliar $\left(\mathrm{cm}^{2}\right)$; e massa seca de folhas, caule, raízes e frutos (g). A área foliar foi determinada com medidor de área foliar LI-3100 (Li-cor, NE) e a massa seca, obtida após secagem em estufa, com circulação de ar forçada a $70^{\circ} \mathrm{C}$, até massa constante, expressas em $g$ planta ${ }^{-1}$; considerou-se como massa seca total o somatório das massas seca de folhas, caule, raiz e frutos, expressa em $g$ planta ${ }^{-1}$.

Para avaliação da produção de frutos, foram colhidos os frutos de cinco plantas úteis, quando apresentavam-se no ponto de colheita comercial, caracterizada no híbrido 'Gold Mine' pela mudança de coloração da casca de verde para amarelo intenso (MENEZES et al., 2000). Foram realizadas dez colheitas de frutos entre os dias 27/02 a 11/03/2006, os quais foram avaliados quanto à produção total e comercial de frutos, expressas em $\mathrm{t}$ $\mathrm{ha}^{-1}$. Foram considerados como comerciais os frutos com atributos mínimos de qualidade e massa fresca, exigidos pelo mercado consumidor, segundo critérios estabelecidos por FILGUEIRAS et al. (2000).

As análises estatísticas foram realizadas utilizando-se o programa SAEG (Sistema de Análises Estatísticas e Genéticas - SAEG/UFV). Para as características quantitativas, foram ajustados modelos não-lineares com curvas do tipo sigmoidais (logística e gompertz); para a características qualitativas, aplicou-se teste de Tukey, adotando-se o nível de 5\% de probabilidade.

\section{RESULTADOS E DISCUSSÃO}

Houve interação significativa $(\mathrm{P}<0,05)$ entre ambientes de cultivo e épocas de amostragem para todas as características de crescimento, partição de assimilados, produção total e comercial de frutos no meloeiro (Figura 1). Também se identificou um aumento crescente em altura de planta até 34,8 DAT sob Aluminet ${ }^{\circledR} ; 31,4$ DAT no Controle; 36,5 DAT sob Cromatinet ${ }^{\circledR}$ e 34,8 DAT sob Sombrite ${ }^{\circledR}$, tendendo para um valor assintótico máximo, com maiores alturas verificados nos ambientes Aluminet ${ }^{\circledR}$ $(262,86 \mathrm{~cm})$ e Controle $(259,93 \mathrm{~cm})$, seguidos dos ambientes Cromatinet ${ }^{\circledR} \quad(240,42 \mathrm{~cm})$ e Sombrite $^{\circledR}$ $(236,73 \mathrm{~cm})$ (Figura 1A).

Maiores valores de comprimento de entrenós também foram obtidos nos ambientes Controle e Aluminet ${ }^{\circledR}$ (Figura 1B), indicando ser esta característica importante na determinação da altura de planta, diferentemente do número máximo de entrenós, com valores semelhantes entre os ambientes de cultivo (Figura 1C). Melhor desempenho em altura de planta nos ambientes Controle e Aluminet ${ }^{\circledR}$, associado ao maior comprimento de entrenós, pode ser atribuído aos maiores valores de radiação solar nesses ambientes de cultivo (Tabela 1). Uma característica da malha Aluminet ${ }^{\circledR}$ é o revestimento aluminizado dos fios retorcidos, que fornecem, em média, 15\% a mais de luz difusa ao ambiente, não afetando assim 

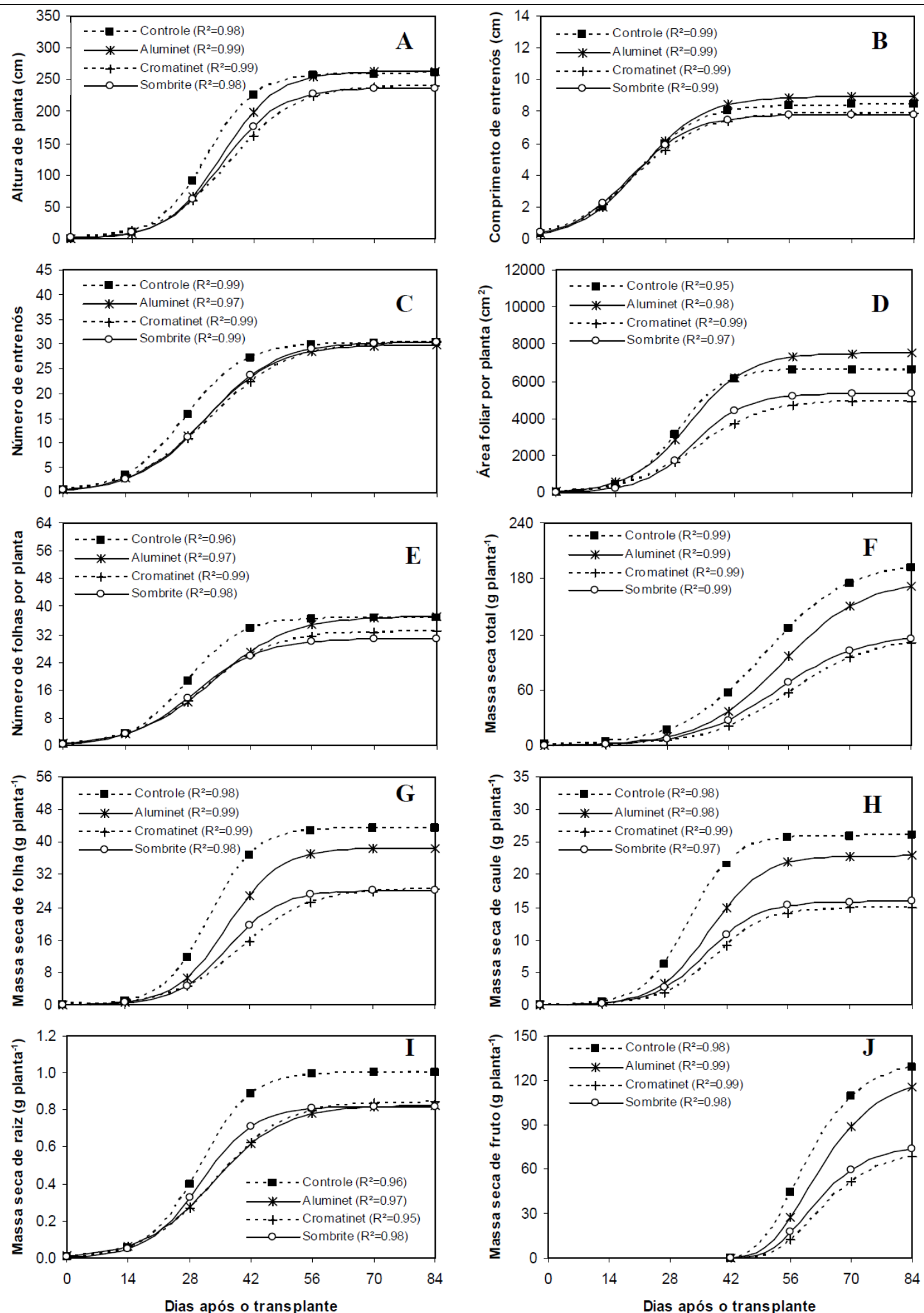

Figura 1 - Altura de planta, comprimento e número de entrenós, área foliar e número de folhas por planta, massas secas total, de folhas, caule, raízes e de frutos de melão híbrido 'Gold Mine' sob cultivos sombreados por diferentes malhas. 
em grande magnitude os processos fotossintéticos e o crescimento das plantas (POLYSACK..., 2013), fato que pode ter propiciado maior crescimento em altura em relação às outras malhas.

Têm-se verificado que o cultivo do meloeiro sob condições de altas irradiâncias aumenta o crescimento da planta em razão de ela apresentar melhor desempenho na síntese e alocação de fotoassimilados (SILVA et al., 2003). Em melão 'Cantaloupe', CARNEIRO FILHO (2000) verificou maior comprimento das hastes e de entrenós sob condições de campo (pleno sol) em relação ao cultivo sob estufa plástica. Outro fator que tem merecido destaque para o meloeiro é a temperatura do solo. Neste trabalho, verificaram-se temperaturas de solo mais elevadas no ambiente controle (Tabela 1), onde ocorreu também maior acúmulo de massa seca de raiz (Figura 1I), comparativamente aos ambientes Aluminet $^{\circledR}$, Cromatinet ${ }^{\circledR}$ e Sombrite ${ }^{\circledR}$. Esse maior crescimento de raiz pode ter proporcionado maior suporte para o crescimento em altura das plantas. $\mathrm{O}$ equilíbrio entre as temperaturas mínimas e máximas do ar também é importante para o crescimento das plantas. Melhor crescimento da cultura do meloeiro situa-se na faixa de temperatura do ar de 18 a $33^{\circ} \mathrm{C}$ (FONTES \& PUIATTI, 2005).

Sob Aluminet ${ }^{\circledR}$, a temperatura do ar ficou dentro da faixa ótima para o meloeiro (Tabela 1). Temperatura do ar abaixo de $18^{\circ} \mathrm{C}$ pode reduzir a translocação de assimilados das folhas-fonte para os diversos órgãos da planta, e acima de $33^{\circ} \mathrm{C}$ promove alta respiração, prejudicando também o desenvolvimento da planta (FONTES \& PUIATTI, 2005). Redução na intensidade luminosa também tem exercido influência negativa sobre o crescimento das plantas de melão (SILVA et al., 2003). No entanto, sob Aluminet ${ }^{\circledR}$, apesar de ter promovido redução da radiação solar PAR, o possível acréscimo da luz difusa nesse tipo de malha pode ter sido importante na modulação morfológica das plantas, por fazer parte desta o comprimento de onda na faixa do vermelhodistante, entre 700 e 800nm (LARCHER, 2000).

Verificou-se incremento na área foliar da planta até 31,38 DAT, 28,6 DAT, 32,5 DAT e 33,2 DAT, respectivamente, sob Aluminet ${ }^{\circledR}$, Controle, Sombrite $^{\circledR}$ e Cromatinet $^{\circledR}$, tendendo para um valor assintótico máximo, com o maior valor sendo verificado sob Aluminet ${ }^{\circledR}\left(7.508,15 \mathrm{~cm}^{2}\right)$, seguido pelos ambientes Controle $(6.637,57)$, Sombrite ${ }^{\circledR}$ $(5.320,63)$ e Cromatinet $^{\circledR}\left(4.934,71 \mathrm{~cm}^{2}\right)$ (Figura 1D). $\mathrm{O}$ maior valor de área foliar por planta verificado sob Aluminet ${ }^{\circledR}$ deveu-se principalmente à maior expansão no limbo foliar, levando-se em consideração que o número máximo de folhas por planta nos ambientes Aluminet ${ }^{\circledR}$ e Controle foram semelhantes (Figura 1E). Os ambientes Cromatinet ${ }^{\circledR}$ e Sombrite ${ }^{\circledR}$ apresentaram menores valores em expansão do limbo foliar e número de folhas por planta em relação aos ambientes Aluminet ${ }^{\circledR}$ e Controle (Figuras 1D e 1E).

O melhor desempenho para área foliar por planta verificado sob Aluminet ${ }^{\circledR}$, associada à maior expansão do limbo foliar, deveu-se ao maior equilíbrio entre as temperaturas máximas e mínimas do ar e ao incremento da luz difusa, uma vez que, segundo POLYSACK (2013), a malha Aluminet ${ }^{\circledR}$ apresenta, em média, de $15 \%$ de luz difusa em relação ao ambiente. Como discutido para a altura de planta, o equilíbrio entre as temperaturas mínimas e máximas do ar e o incremento na luz difusa pode ter tido papel importante na modulação morfológica da planta. Parte da luz difusa fornecida pelo Aluminet ${ }^{\mathbb{R}}$ é composta pelo comprimento de onda na faixa do vermelho-distante entre 700 e 800nm (LARCHER, 2000). Maior proporção de luz vermelho-distante, em relação ao vermelho, parece regular não somente a taxa de alongamento do caule, mas também a expansão do limbo foliar, mediada pelo fitocromo (TAIZ \& ZEIGER, 2009). O fitocromo apresenta dois sítios de absorção de luz: no vermelho (pr) e no vermelho-distante (pfr). Quando as plantas são submetidas à maior quantidade de luz vermelhodistante, ocorre a conversão do fitocromo de pfr para pr e a razão pfr/fitocromo total diminui. Acredita-se que a diminuição nessa relação induz a síntese de giberelinas e, consequentemente, também o aumento na divisão e, principalmente, na expansão celular (TAIZ \& ZEIGER, 2009). Esse tipo de modulação morfológica parece ter sido evidenciada no meloeiro, quando cultivado sob Aluminet ${ }^{\circledR}$, o que proporcionou maior aproveitamento da luz, como observado pelo acúmulo de massa seca total na planta (Figuras 1A e 1B). A menor área foliar do Controle, em relação ao Aluminet ${ }^{\circledR}$, pode estar relacionada à estratégia da planta para evitar grandes áreas de exposição a condições de altas irradiâncias, a qual poderia resultar em aumento nos gastos energéticos para manutenção dos processos de proteção da planta, como síntese de pigmentos carotenoides e enzimas envolvidas na proteção foto-oxidativa (LARCHER, 2000). No entanto, os maiores valores de temperatura do solo sob condições de pleno sol no meloeiro parecem não ter exercido influência no aumento da área foliar da planta, principalmente, quando comparado ao Aluminet $^{\circledR}$, indicando que existe uma faixa adequada de temperatura que permite o crescimento equilibrado de partes aérea e subterrânea. 
Menores valores de área foliar nos ambientes sob Cromatinet ${ }^{\circledR}$ e Sombrite ${ }^{\circledR}$ parecem estar relacionados não só com a redução na intensidade, mas também com a qualidade da luz. RANSMARK (1995) verificou que o aumento na luz azul sob condições de baixa irradiância afetou o crescimento do meloeiro. Segundo TAIZ \& ZEIGER (2009), condições artificiais que favorecem o aumento de luz azul em detrimento da redução da luz vermelha no ambiente pode causar diminuição, tanto na taxa de divisão como de alongamento celular. CARNEIRO FILHO (2000), trabalhando com melão, verificou menor área foliar e número de folhas por planta sob baixas intensidades luminosas, concluindo que ela foi insuficiente na promoção da síntese dos fotoassimilados, requeridos nos processos de crescimento das referidas plantas.

Verificou-se incremento na massa seca total até 59,9 DAT no Controle, 53,7 DAT no Aluminet $^{\circledR}, 52,5$ DAT no Sombrite ${ }^{\circledR}$ e 55,3 DAT no Cromatinet $^{\circledR}$, tendendo para um valor assintótico máximo, com os maiores valores sendo verificados sob condições de pleno sol $\left(192,07 \mathrm{~g}\right.$ planta $\left.{ }^{-1}\right)$, seguidos pelos ambientes Aluminet ${ }^{\mathbb{B}}(171,37)$, Sombrite $^{\circledR}(115,36)$ e Cromatinet ${ }^{\circledR}\left(110,58\right.$ g planta $\left.^{-1}\right)$ (Figura $1 \mathrm{~F}$ ). Maior valor de massa seca total, obtida sob condições de pleno sol, resultou das maiores massas seca de folhas, caule, raízes e frutos, em relação aos ambientes Aluminet ${ }^{\circledR}$, Sombrite ${ }^{\circledR}$ e Cromatinet $^{\circledR}$ (Figura 1G, H, I e J).

Melhor desempenho no acúmulo de massa seca total nas plantas de meloeiro sob condições de pleno sol pode ser atribuído à maior radiação solar e seu aproveitamento pelas folhasfonte e ao maior crescimento do sistema radicular, com melhor aproveitamento dos recursos do solo. Essas condições permitiram incremento precoce no número e massa de folhas por planta e, também, na obtenção de seu valor assintótico máximo. Essa combinação de resultados pode ter proporcionado maior suporte para o melhor desempenho no acúmulo de massa seca nos diversos órgãos da planta de melão sob condições de pleno sol. Sob Aluminet $^{\circledR}$, alterações morfológicas na planta, como maior expansão do limbo foliar proporcionadas principalmente pelo equilíbrio na temperatura do ar e luz difusa em relação às outras malhas, podem ter contribuído para o maior incremento na massa seca total, folha, caule e fruto, em relação aos ambientes Cromatinet $^{\circledR}$ e Sombrite $^{\circledR}$ (Figura 1F, G, H e J).

$\mathrm{O}$ acúmulo de massa seca na planta é resultado do balanço entre a radiação fotossinteticamente ativa incidente e a absorvida pelas folhas, da eficiência média de conversão da radiação absorvida em massa seca e da partição desta entre as partes coletoras de luz, as folhas, e o restante da planta (TEI et al., 1996). Portanto, a maior síntese de fotoassimilados e a partição equilibrada destes entre os diversos órgãos da planta, sob condições de pleno sol, proporcionaram maior precocidade no incremento e também na obtenção dos valores de máximo de massa seca de folha, caule, raiz, fruto e total em relação aos ambientes sombreados no meloeiro. CARNEIRO FILHO (2000) também verificou incremento na massa seca de parte aérea no meloeiro cultivado sob condições de campo (pleno sol) em relação ao cultivo sob estufa plástica.

Os ambientes Controle e Aluminet ${ }^{\circledR}$ proporcionaram os maiores valores de produção total e comercial de frutos em relação aos ambientes Cromatinet $^{\circledR}$ e Sombrite (Figura 2). No Controle, a maior radiação solar e o incremento mais precoce no número de folhas por planta e também no seu valor assintótico máximo (Figuras 1E) podem ter proporcionado maior suporte ao crescimento $\mathrm{e}$ acúmulo de massa seca nos frutos, pelo melhor aproveitamento da radiação solar. Sob Aluminet ${ }^{\circledR}$, a maior expansão do limbo foliar, favorecidos pelo equilíbrio na temperatura do ar e pela luz difusa no ambiente com Aluminet ${ }^{\circledR}$, parece ter compensando a redução da radiação solar, resultando em maiores produções em relação aos ambientes Cromatinet ${ }^{\mathbb{B}}$ e Sombrite ${ }^{\circledR}$.

Portanto, sob condições de céu limpo, sem nuvens, acredita-se que a redução na radiação solar pelas malhas não teria prejudicado o processo fotossintético e, consequentemente, o crescimento e a produção de frutos no meloeiro, em razão dessas proporcionarem valores de radiação incidente dentro da faixa ótima de luz exigida pela cultura. No entanto, verificou-se que, durante os 90 dias de condução do experimento, a insolação média diária foi inferior a 5 horas $(4,47)$, bem abaixo da região semiárida do nordeste, que está em torno de 9 horas (SILVA et al., 2003). Portanto, sob condições de dias nublados, a redução adicional na radiação solar, proporcionada pelas malhas, pode ter limitado o processo fotossintético e, consequentemente, o crescimento e a produção de frutos no meloeiro, devido ao fato de a radiação incidente, nesses ambientes, ter caído a valores aquém do ponto de saturação luminoso, o que pode ter mascarado, em parte, o efeito benéfico dessas malhas. 


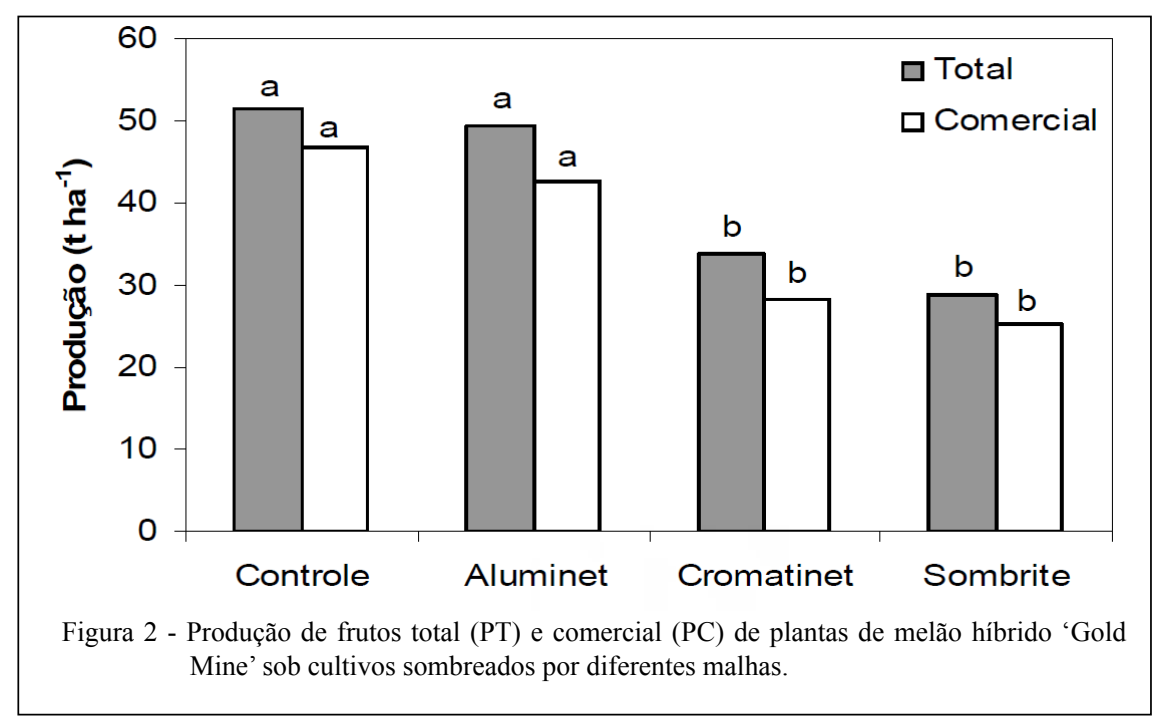

\section{CONCLUSÃO}

Dentre os ambientes sombreados, o cultivo do meloeiro sob a malha Aluminet ${ }^{\mathbb{B}} 30 \%$-O foi o que mais se destacou em termos de crescimento de planta e produção de frutos.

Os fatores climáticos registrados em cada ambiente de cultivo interferiram decisivamente sob o crescimento de planta e massa seca do meloeiro. O bom desempenho em crescimento e produção do meloeiro, quando sombreado em $30,85 \%$ pelo Aluminet ${ }^{\circledR} 30 \%$-O, abre perspectivas para cultivo sombreados (consórcio e sistemas agroflorestais).

\section{AGRADECIMENTOS}

Os autores agradecem ao Conselho Nacional de Desenvolvimento Científico e Tecnológico (CNPq) pelo auxílio financeiro na condução da pesquisa.

\section{REFERÊNCIAS}

BRANT, R.S. et al. Adaptações fisiológicas e anatômicas de Melissa officinalis L. (Lamiaceae) cultivadas sob malhas termorrefletoras em diferentes intensidades luminosas. Revista Brasileira Plantas Medicinais, v.13, n.4, p.467-474, 2011. Disponível em: <http://dx.doi.org/10.1590/S151605722011000400012>. Acesso em: 20 jan. 2013. doi: 10.1590/ S1516-05722011000400012.

CARNEIRO FILHO, J. Produção e qualidade de frutos de melão cantaloupe influenciadas pela poda e pelo tutoramento, em condições de estufa e campo. 2000. 120f. Dissertação (Mestrado em Fitotecnia) - Universidade Federal de Viçosa, Viçosa, MG.
FILGUEIRAS, H.A.C. et al. Colheita e manuseio pós-colheita. In: ALVES, R.E. (Ed.). Melão pós-colheita. Brasília: Embrapa Comunicação para Transferência de Tecnologia, 2000. p.23-41.

FONTES, P.C.R.; PUIATTI, M. Cultura do melão. In: FONTES, P.C.R. (Ed.). Olericultura: teoria e prática. Viçosa: UFV, 2005. p.407-428.

LARCHER, W. Ecofisiologia vegetal. 3.ed. São Carlos: Rima, 2000. 531p. (Trad. Carlos Henrique B.A. Prado).

MENEZES, J.B. et al. Característica do melão para exportação. In: ALVES, R.E. (Ed.). Melão pós-colheita. Brasília: Embrapa Comunicação para Transferência de Tecnologia, 2000. p.13-22.

PEREIRA, F.H.F. et al. Growth, assimilate partition and yield of melon charenthais under different shading screens. Horticultura Brasileira, v.29, p.91-97, 2011. Disponível em: <http://dx.doi. org/10.1590/S0102-05362011000100015>. Acesso em: 20 jan. 2013. doi: $10.1590 / \mathrm{S} 0102-05362011000100015$.

POLYSACK INDÚSTRIA LTDA. Hortaliças e hidroponia. Disponível em: $<$ http://www.polysack.com.htm $>$. Acesso em: 22 out. 2013.

RANSMARK, S.E. The influence of light intensity on photosynthesis and photosynthetic yield. Swedish University of Agricultural Sciences: Department of Agricultural Biosystems and Technology, 1995. 31p.

RIBEIRO, A.C. et al. Recomendação para o uso de corretivos e fertilizantes em Minas Gerais. Viçosa: UFV, 1999. 359p.

SILVA JÚNIOR, J.M. et al. Variações anatômicas de Laelia purpurata var. cárnea cultivada in vitro sob diferentes intensidades e qualidade spectral de luz. Ciência Rural, v.42, n.3, p.480486, 2012. Disponível em: <http://dx.doi.org/10.1590/S0103$84782012000300015>$. Acesso em: 20 jan. 2013. doi: 10.1590/ S0103-84782012000300015. 
SILVA, H.R.; COSTA, N.D. Exigências de clima e solo e época de plantio. In: (Eds.). Melão produção: aspectos técnicos. Brasília: Embrapa Informação Tecnológica, 2003. p.23-28.

TAIZ, L.; ZEIGER, E. Fisiologia vegetal. Porto Alegre: Artmed, (2009). 819p.

TEI, F. et al. Growth of lettuce, onion and red beet. 1. Growth analysis, light interception, and radiation use efficiency. Annals of Botany, v.78, p.633-643, 1996. Disponível em: <http://dx.doi. org/10.1006/anbo.1996.0171>. Acesso em: 20 set. 2012. doi: 10.1006/anbo.1996.0171.

VALANTIN, M. et al. Changing sink demand affects the area but not the specific activity of assimilate sources in cantaloupe (Cucumis melo L.). Annals of Botany, v.82, p.711-719, (1998). Disponível em: <http://www.researchgate.net/profile/ Marc_Tchamitchian/publication/31292685_Changing_Sink_ Demand_Affects_the_Area_but_not_the_Specific_Activity_ of_Assimilate_Sources_in_Cantaloupe_(Cucumis_meloL.)/ links/09e4150a5ef520965f000000.pdf>. Acesso em: 20 set. 2012. 